\title{
Heracleópolis Magna y el comercio fenicio en Egipto
}

\author{
Josep PADRo *
}

Tras algunos años de inactividad, la Misión Arqueológica Española en Egipto ha reemprendido regularmente sus trabajos desde 1984 en el yacimiento de Heracleópolis Magna, proporcionando algunas novedades interesantes entre las que cabe destacar la identificación de niveles pertenecientes al 3 . $^{\text {er }}$ Periodo Intermedio. Algunos hallazgos efectuados en dichos niveles consisten en cerámicas fenicias: de ellas, y de las implicaciones históricas que pueden deducirse de su presencia en Egipto, quiero hablar en este breve trabajo dedicado en homenaje al Dr. Ripoll.

El yacimiento de Heracleópolis Magna (Ehnasia el-Medina, provincia de Beni-Suef) es uno de los mayores de Egipto (López, 1974: 299). Se encuentra en el Egipto Medio, a poco más de $140 \mathrm{~km}$. al Sur del Cairo y muy cerca del oasis del Fayum, sobre la orilla derecha del Bahr Yusef pero aún en el mismo valle del Nilo, justo en uno de los lugares en que éste alcanza mayor anchura.

Desde el punto de vista histórico, Heracleópolis es célebre sobre todo por el hecho de haber sido la capital de Egipto durante las Dinastias IX y X (siglos XX\| y XXI a J.C.) en el 1. ${ }^{\text {er }}$ Período Intermedio, pero también se sabe que fue capital de un principado llegando a ser independiente durante el 3. ${ }^{\text {er }}$ Período Intermedio, más concretamente en la llamada Época Libia.

Las sucesivas investigaciones emprendidas en el yacimiento desde finales del siglo XIX se habian ocupado tan sólo de ciertos monumentos

\footnotetext{
* Universidad de Barcelona.
} 


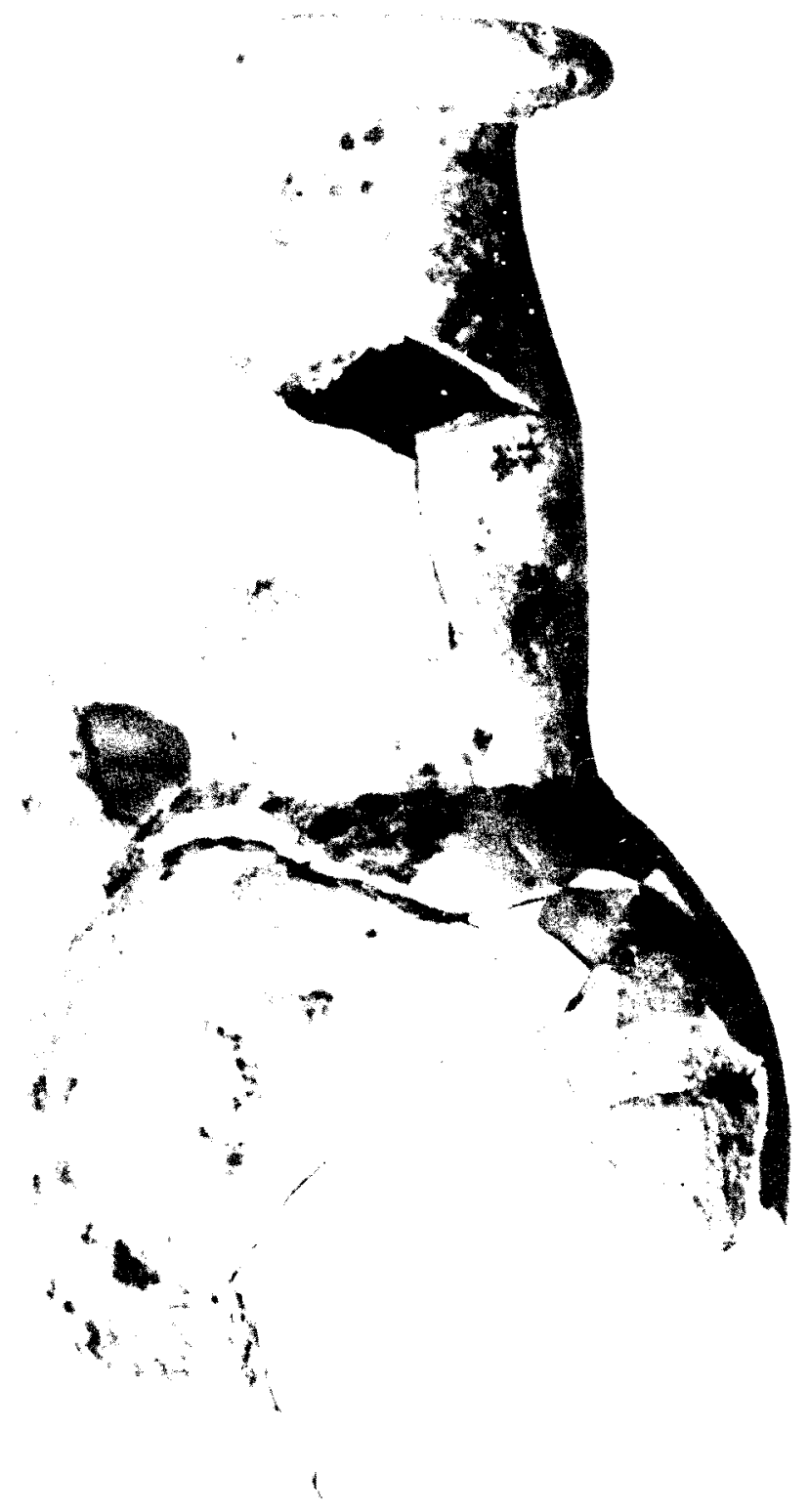

Fig. 1. Oinócoe fenicio del sondeo $\mathrm{H}$ de Heracleópolis Magna. 

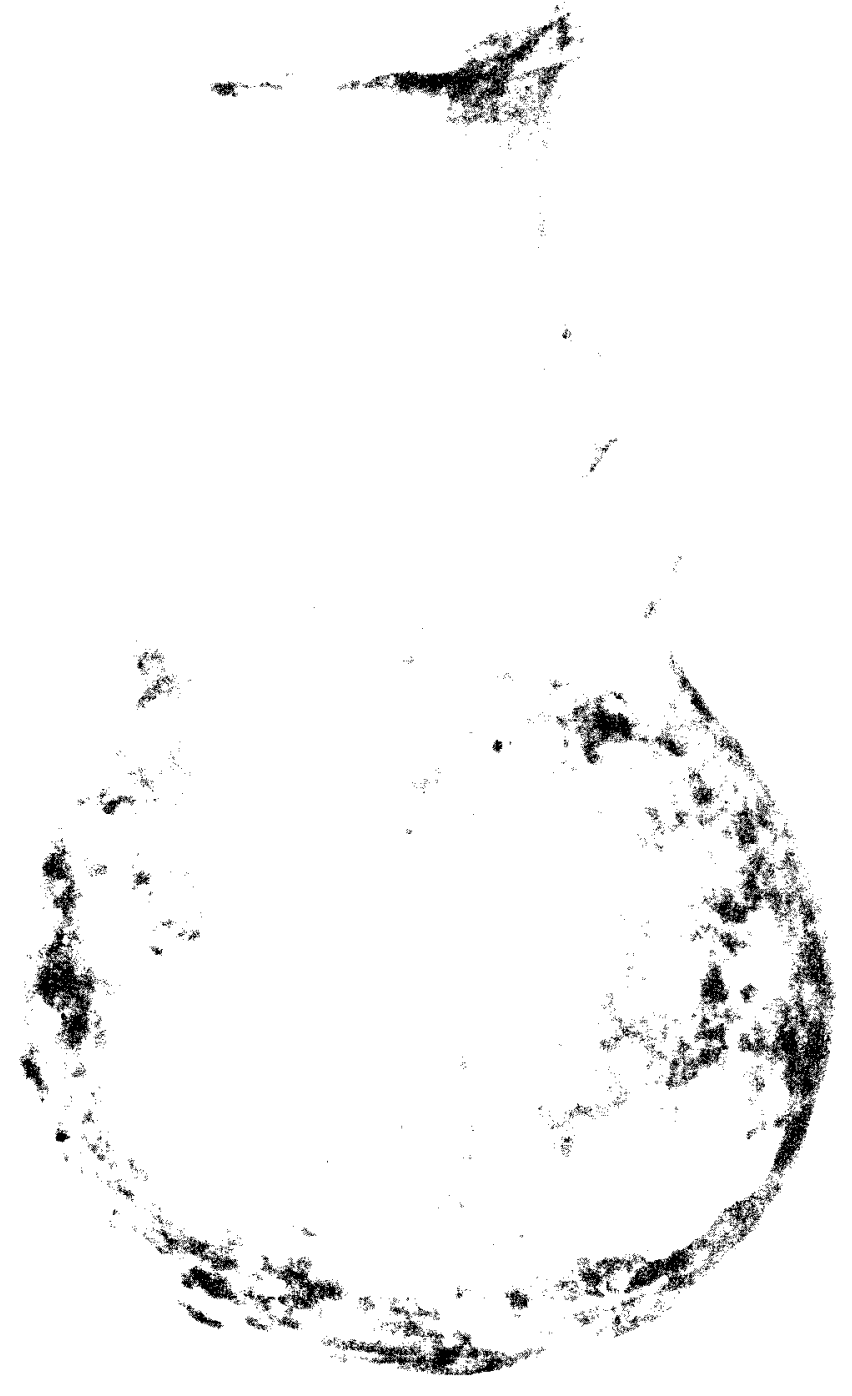

Fig. 2. Oinócoe fenicio del sondeo $H$ de Heracleópolis Magna. 


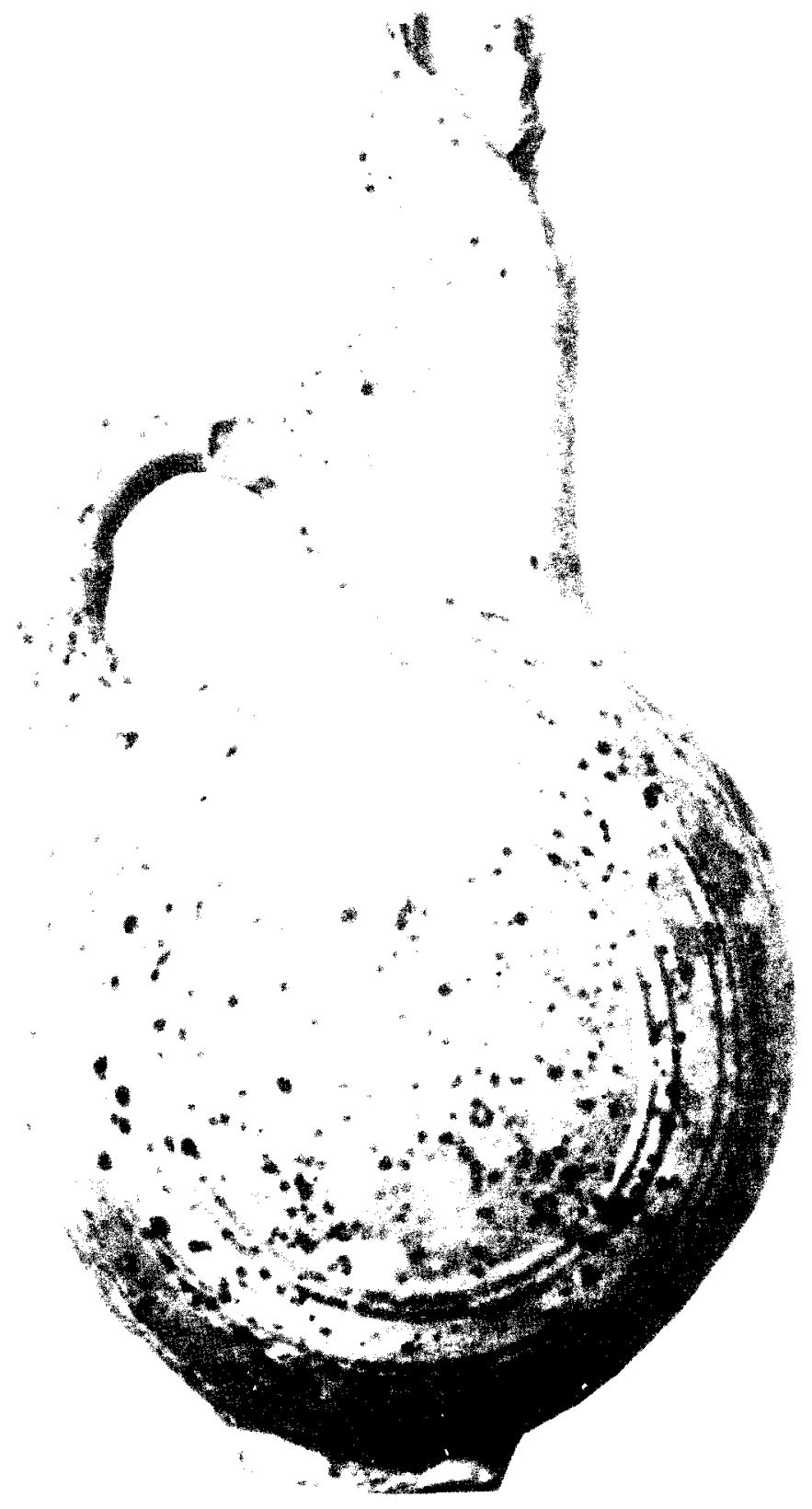

Fig. 3. Oinócoe fenicio-chipriota del sondeo H de Heracleópolis Magna. 


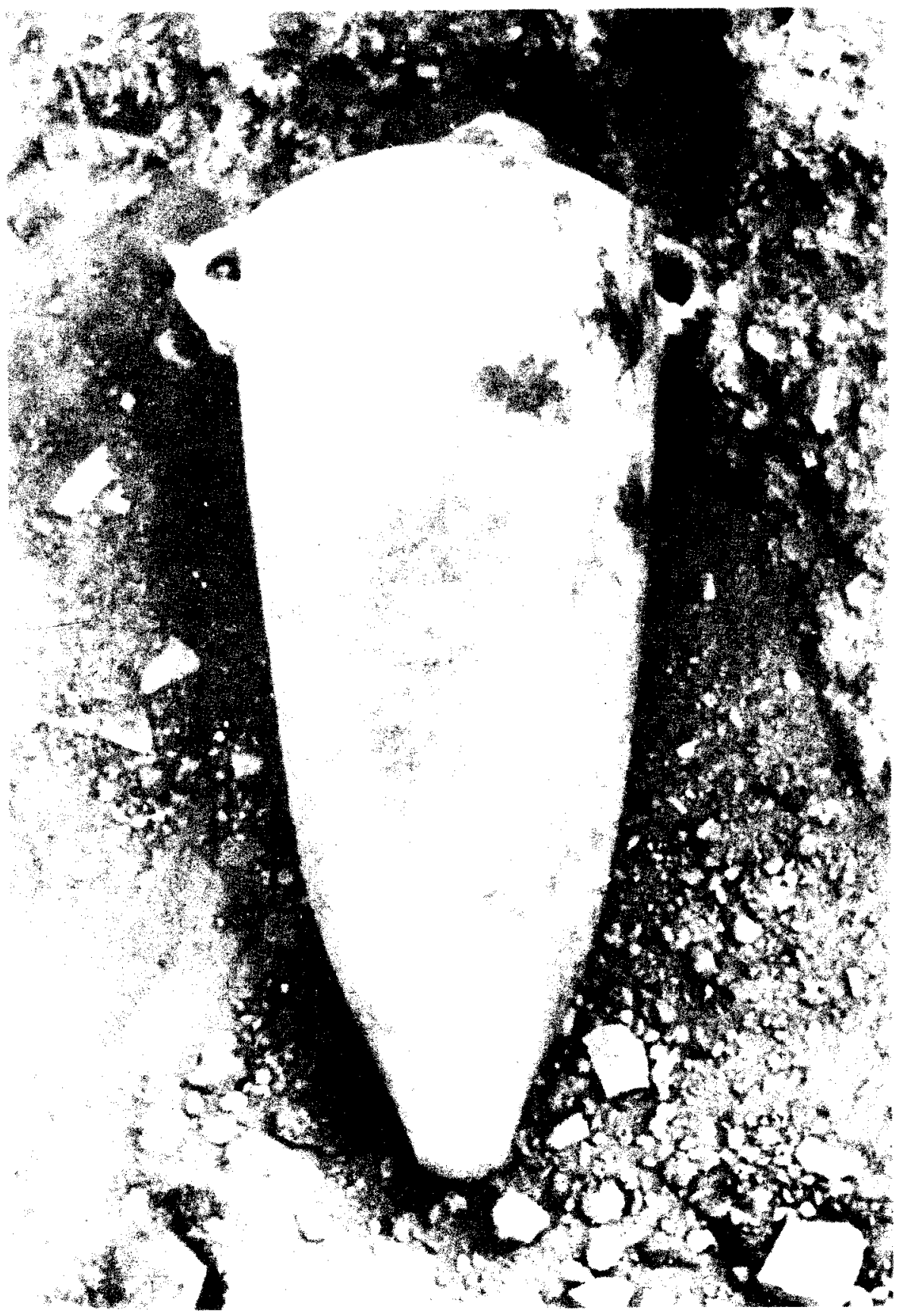

Fig. 4. Antora tenicia del sondeo $\mathrm{H}$ de Heracleopolis Magna. 
JOSEP PADRO

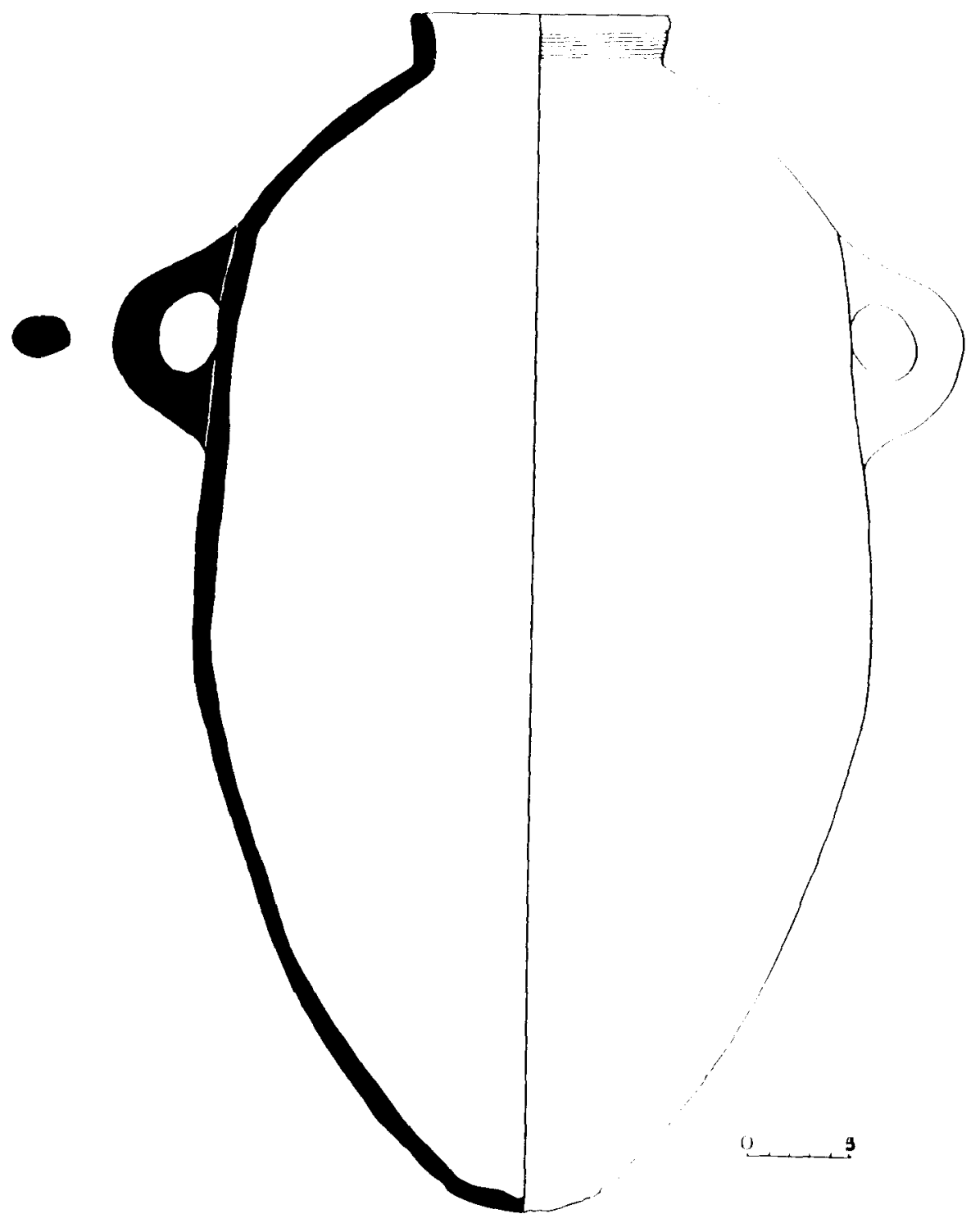

Fig. 5. Anfora fenicia del sondeo / de Heracleópolis Magna.

50 


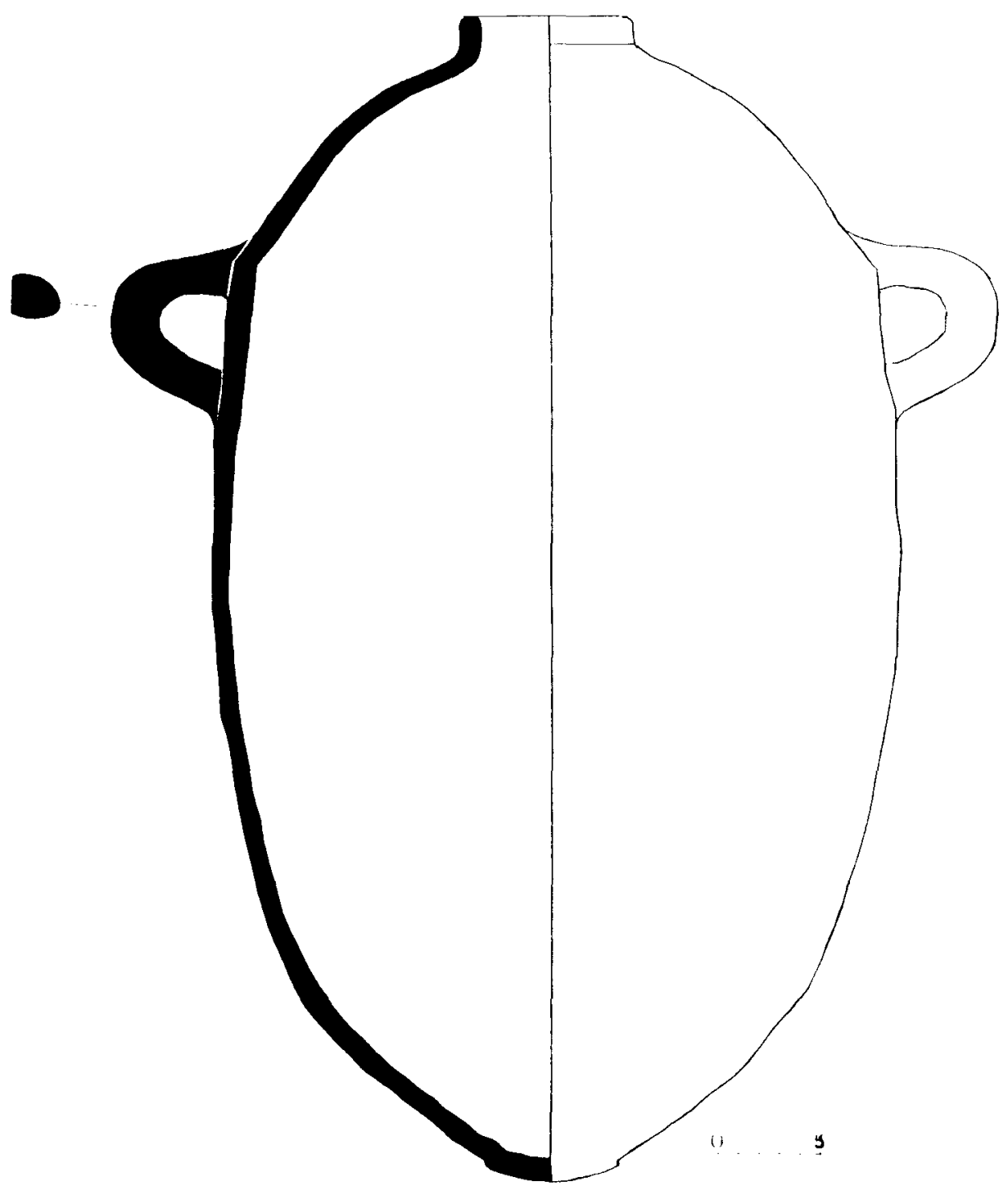

Fig. 6. Ánfora fenicia del sondeo / de Heracleópolis Magna. 


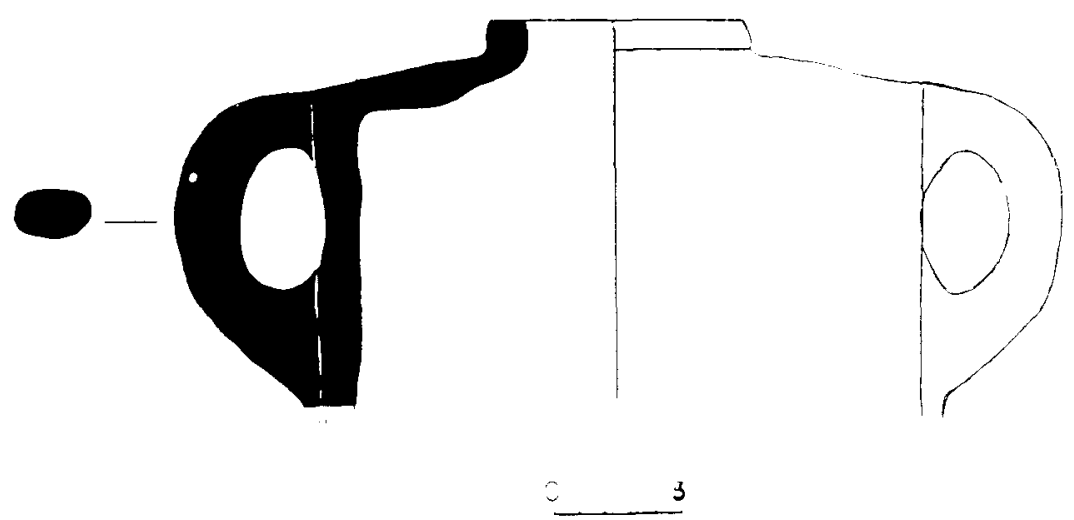

Fig. 7. Fragmento de anfora fenicia del sondeo I de Heracleopolis Magna.

de época faraónica, romana y copta, asi como de algunas casas romanas (Mokhtar. 1983: 71-96). En 1966 la Misión Arqueológica Española emprendió a su vez sus propios trabajos, que desde 1968 se ocuparon preferentemente de una necrópolis del 1 . $^{\text {r }}$ Período Intermedio (López, 1974: 299-316: López, 1975: 57-78; Almagro y Presedo, 1979: 67-71: Presedo, 1979: 525-532). Con todo, un sondeo de exploración emprendido en 1977 reveló la presencia de un recinto sagrado con material perteneciente al 3." Periodo Intermedio.

Reemprendidos los trabajos en 1984, nuestra Misión ha emprendido el ensanchamiento de este sondeo (Padró y Pérez Díe, 1985: 165-166; Padró y Pérez Díe, 1989: en prensa), donde las excavaciones conducidas por Pérez Díe desde 1985 han puesto al descubierto una necrópolis de cámaras muy semejante a la de Tanis (Pérez Die, 1985: 172-173; Pérez Die, 1986: 10-13; Pérez Die, 1987: 44-49; Pérez Die, 1989: en prensa). Desgraciadamente, casi todas las cámaras excavadas hasta ahora han sido halladas totalmente saqueadas, pero tanto la documentación epigráfica como los numerosos ushebtys encontrados nos informan de que se trata de una necropolis perteneciente a la Época Libia, en la que fueron enterrados sin duda algunos miembros de las familias reales de las Dinastias XXII y XXIII (siglos $X$ a VIII a J.C.).

En 1984 hemos excavado algunas construcciones anexas inmediatas a este conjunto funerario y sagrado - sondeo $\mathrm{H}-$, y en ellas hemos descubierto algunos oenochoae (figs. 1-3) fenicios y chipriotas (Pérez Die, 1987: 48 y 2. fig. de la pág. 49), con paralelos en Tiro en los niveles III -del siglo VIII (Bikai, 1978: 67, lám. V)-y IX-de los siglos Ix y VIII 


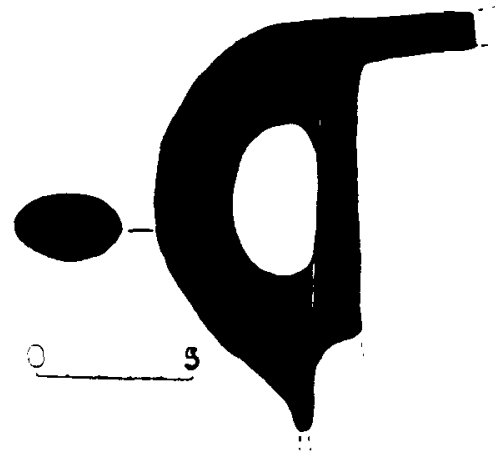

Fig. 8. Fragmento de ánfora fenicia del sondeo / de Heracleópolis Magna

(Bikai, 1978: 67, lám. XXI)--, asi como un ánfora fenicia (fig. 4) con paralelos también en Tiro en el nivel IX (Bikai, 1978: lám. XXI).

Por otro lado, en 1985 y 1986 hemos continuado la excavación de un barrio de casas, cercano a la Muralla Sur - sondeo l- y a cierta distancia de los hallazgos anteriores, excavación que también habiamos iniciado en 1984 (Padró y Pérez Die, 1985: 165-166; Padró y Pérez Die, 1989: en prensa). Actualmente podemos fechar este barrio también de Época Libia, ya que en una de las casas hemos recogido diversos fragmentos pertenecientes como minimo a cuatro ánforas fenicias (figs. 5-8), todas ellas con paralelos asimismo en el propio nivel IX de la estratigrafia de Tiro (Bikai, 1978: lám. XXI), nivel que puede fecharse de los siglos IX y vIII a J.C. (Bikai, 1978: 67).

El sorprendente hallazgo de estos elementos fenicios en Heracleópolis se ve sin duda realzado por el hecho de tratarse de la primera vez, que nosotros sepamos, que se señala la presencia de importaciones fenicias en el Egipto Medio. Sin embargo, el hallazgo no deja de ser lógico si tenemos en cuenta las relaciones privilegiadas que Egipto mantenía con Fenicia justamente en Época Libia (Leclant, 1968: 9-14). Incluso si aceptamos que la llegada de objetos fenicios a Heracleópolis puede justificarse por el hecho del papel ciertamente importante jugado por la ciudad en esta época, aún asi es preciso reconocer que se encuentra muy al Sur: si una cierta cantidad de importaciones fenicias llegaban durante los siglos ix y vill hasta una localidad situada a unos $100 \mathrm{~km}$. al Sur de Menfis, es fácil imaginar la envergadura que el comercio fenicio podia alcanzar en la misma Menfis. Además, la reciprocidad de estos intercambios comerciales está probada como mínimo por la presencia de objetos 
egipcios en Tiro en contacto con las ánforas y los oenochoae que hemos citado como paralelos a los hallazgos heracleopolitanos: del nivel VIII-IX de Tiro provienen dos escarabeos (Bikai, 1978: lám. XXI) y del nivel III un fragmento de vaso de piedra con inscripción jeroglífica, fechado en el siglo VIII a J.C. (Bikai, 1978: lám. XIII, y 67).

En varias ocasiones hemos sostenido que la llegada de grandes vasos egipcios de piedra a diversos yacimientos fenicios del Mediterráneo occidental como Almuñécar, por ejemplo, debe explicarse como resultado de la intensificación de los intercambios comerciales regulares entre Egipto y Fenicia durante los siglos Ix y VIII a J.C., opinión que se contradice con la de algún otro autor (Gamer-Wallert, 1978: 41-42; Padró, 1982-1983, 153-154 y 157-158). Para nosotros, la razón de ser de este comercio no sería otra que el aprovisionamiento de bronce a Egipto por parte de los fenicios, lo que explicaría al mismo tiempo la aparición de una gran estatuaria en bronce en Egipto precisamente en Época Libia, y la expansión de la colonización fenicia en el Occidente productor de metales durante los siglos IX y VIII. Estas relaciones comerciales privilegiadas habrian hecho de Egipto, por consiguiente, el principal cliente de los fenicios, y quizás también el motor económico de la expansión colonial fenicia (Padró, 1979: 507-514; Padró, 1976-78: 507-508; Padró, 1983: 7374; Padró, 1984: 159-165; Padró, 1987: 213-222). Ahora creemos estar en condiciones de asegurar que el reciente hallazgo de cerámicas fenicias en un lugar como Heracleópolis y en los siglos IX y VIII prueba fehacientemente la importancia de estas relaciones comerciales entre egipcios y fenicios durante la Época Libia. 


\section{BIBLIOGRAFIA}

Almagro, M. y Presedo, F., 1979: Les Fouilles è Hérakléopolis Magna (1976). Acts of the First International Congress of Egyptology, Cairo, 1976. Shcriften zur Geschichte und Kultur des Alten Orients, 14. Berlin: 67-71.

BIKAI, P. M., 1978: The Pottery of Tyre. Warminster.

GAMER-WALleRT, I., 1978: Ägyptische und ägyptisierende Funde von der Iberischen Halbinsel. Beihefte zum Tübinger Atlas des Vorderen Orients, Reihe B, N. ${ }^{\circ} 21$, Wiesbaden.

LECLANT, J., 1968: Les Relations entre l'Egypte et la Phénicie du voyage d'Ounamon à l'expedition d'Alexandre. The Role of the Phoenicians in the Interaction of Mediterranean Civilizations. Beirut: 9-31.

LOPEZ, J., 1974: Rapport préliminaire sur les fouilles d'Hérakléopolis (1966). Oriens Antiquus, XIII: 299-316.

LOPEZ, J., 1975: Rapport préliminaire sur les fouilles d'Hérakléopolis (1968). Oriens Antiquus, XIV: 57-78.

Mokhtar, M. G. E., 1983: Ihnâsya el-Medina (Herakleopolis Magna). Its Importance and its Role in Pharaonic History. Bibliothèque d'Étude, $\mathrm{XL}$. EI Cairo.

PADRO i PARCERISA, J., 1976-78: Datos para una valoración del "factor egipcio" y de su incidencia en los origenes del proceso de iberización. Ampurias, 38-40. Simposi Internacional: Els Origens del Món Ibèric, Barcelona-Empúries, 1977. Barcelona: 487-509.

-, 1979: À propos des trouvailles égyptiennes dans la Péninsule Ibérique: Considerations sur les relations de l'Égypte avec l'Occident de l'Europe à la Basse Époque. Acts of the First International Congress of Egyptology, Cairo, 1976. Shcriften zur Geschichte und Kultur des Alten Orients, 14. Berlín: 507-514. 
- 1982-1983: De nuevo sobre los hallazgos egipcios y egiptizantes de la Península Ibérica. Cuadernos de Prehistoria y Arqueologia CasteIlonenses, 9: 149-191.

—, 1983: Los Fenicios y la distribución de objetos egipcios en el extremo occidente mediterráneo. Atti del / Congresso Internazionale di Studi Fenici e Punici, Roma, 1979, vol. I. Roma: 67-75.

-, 1984: El Paper d'Egipte en el comerç dels metalls d'Occident a la Baixa Ėpoca. Cuadernos de Prehistoria y Arqueologia Castellonenses, 10: 159-165.

-, 1987: Le Rôle de l'Égypte dans les relations commerciales d'Orient et d'Occident au Premier Millénaire. Annales du Service des Antiquités de l'Égypte, LXXI: 213-222.

PAdRo, J. y PÉrez Die, M. C., 1985: Recents travaux archéologiques de la Mission Espagnole à Héracléopolis Magna. Fourth International Congress of Egyptology, Munich, 1985, Abstracts of Papers. Munich: 165-166.

—, 1989: Travaux recents de la Mission Archéologique Espagnole à Héracléopolis Magna. Akten des Vierten Internationalen AgyptologenKongresses, München, 1985. Studien zur Altägyptischen Kultur Beihefte, vol. 2. Hamburgo: en prensa.

Pérez Die, M. C., 1985: Nouveaux documents de la Troisième Période Intermédiaire provenant d'Héracléopolis Magna. Fourth International Congress of Egyptology, Munich, 1985. Abstracts of Papers. Munich: 172-173.

-, 1986: Les Excavacions de la Missió Arqueològica Espanyola a Heracleòpolis Magna (Egipte). Quaderns de la Fundació Caixa de Pensions, 32 (2. ${ }^{a}$ època): 10-13.

-, 1987: Hérakléopolis Magna, une cité prospère aux portes du Fayoum. Archeologia, 225: 36-49.

-, 1989: Documents nouveaux de la Troisième Période Intermédiaire provenant d'Héracléopolis Magna. Akten des Vierten Internationalen Ägyptologen-Kongresses, Müchen, 1985. Studien zur Altägyptischen Kultur Beihefte, vol. 2. Hamburgo: en prensa.

Presedo Velo, F. J., 1979: Les Dernières découvertes à Hérakléopolis Magna. Acts of the First International Congress of Egyptology, Cairo, 1976. Schriften zur Geschichte und Kultur des Alten Orients, 14. Berlín: 525-532. 